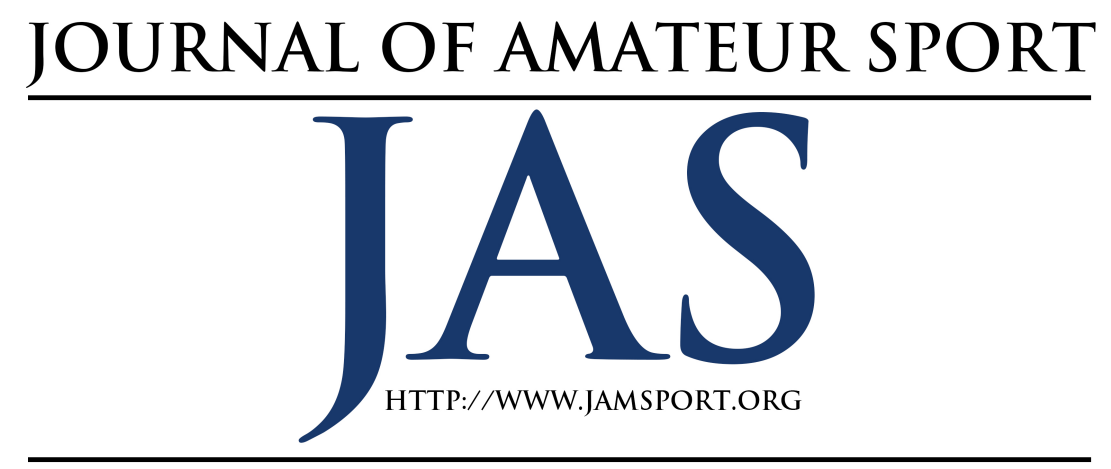

\title{
Sport and Family Functioning: Strengthening Elite Sport Families
}

\author{
Michael Newhouse-Bailey ${ }^{1} \quad$ Marlene A. Dixon ${ }^{2}$ \\ Stacy Warner ${ }^{3}$ \\ ${ }^{1}$ Southern New Hampshire University \\ ${ }^{2}$ Troy University \\ ${ }^{3}$ East Carolina University
}

Families play an important role in society, both in human sustenance and individual development. Family systems theory views the family as a series of interconnected parts that when functioning properly, provide individual members with multiple benefits. Interaction with external systems, such as sport, school or church, can have positive and negative impacts on the family. It is unclear, however, what elements of sport relate to specific outcomes. The purpose of this study is to better understand the relationship between elite youth sport participation and family units, and how these two spheres, individually and in combination, impact family functioning. Indepth, purposeful interviews with seven "sport families" revealed that in addition to the depletion of resources (financial and time), elite sport engagement strongly detracts from the marital dyad and family unit receiving sufficient time and attention for proper functioning. The results also offer insight into how the leagues can be better managed such that they positively contribute to family functioning. Specifically, the results indicate that leagues can aid in strengthening family functioning through allowing families to have coaching input, and providing greater attention to scheduling, league expectations, and instrumental support.

$\mathrm{F}$ amilies play a vital role in our society by providing members with a means of financial, social, and emotional support as well as personal development (Bebiroglu, Geldhof, Pinderhughes, Phelps,
\& Lerner, 2013; Lavee, McCubbin \& Olsen, 1987; Minuchin, 1985). Researchers and practitioners continue to find ways to enhance family functioning on the basis that more functional families lead to greater 
well-being for family members and ultimately to a healthier and more stable society (Freistadt \& Strohschein, 2012). One avenue that has often been proposed for families to achieve greater functioning is to play or recreate together.

Family scholars have established that there is a positive relationship between family leisure activities and positive family outcomes (e.g., Orthner \& Mancini, 1991; Zabriskie \& McCormick, 2001). For example, in a 5-year longitudinal study, Hill (1988) found a significant relationship between shared leisure time and lower divorce and separation rates. Zabriskie and McCormick (2001) found that different types of family leisure activities have the ability to strengthen the bonds within a family and allow the family to become better at adapting to new situations. The leisure context provides a safe environment to enhance communication and adaptability, and shared activities can increase bonding within the family and enhance overall family cohesion (Orthner \& Mancini, 1991).

Current trends indicate that one leisure context in which an increasing number of families are interacting with is youth sport (Dorsch, Smith, \& McDonough, 2009; Lally \& Kerr, 2008; Warner, Dixon, \& Leierer, 2015). Youth sport provides a context in which many positive outcomes may occur for the child participant (Dixon \& Bruening, 2011; Ewing, Gano-Overway, Branta, \& Seefeldt, 2002; Warner \& Leierer, in press). These include, but are not limited to, physical fitness, self-esteem, social skills and the ability to make moral decisions (Ewing et al., 2002). Parents often enroll their children in sport leagues in the hopes that the child will reap these positive benefits and maintain a healthy lifestyle (Coakley, 2006; Dixon, Warner, \& Bruening, 2008; Fredricks \& Eccles, 2004). This research has shown, however, that positive development does not automatically occur for children enrolled in sport (Chalip, 2006; Hartmann, 2003; Warner et al., 2015). In fact, many negative outcomes are also associated with youth sport, including cheating, high injury rates, high burnout, and a drain on family resources such as time and money (Côté, 1999; Frey \& Eitzen, 1991; Thompson, 1999).

Research also supports that organized sport may provide parents an opportunity to contextualize parenting behaviors through sport (Dorsch, Smith, \& McDonough, 2015). Thus, family communication is enhanced as parents use sport as a vehicle to teach life lessons. Clearly, not all leisure activities are equal when it comes to their impact on individual and/or family functioning. Further, current U.S. trends indicate an increase in youth sport specialization and elite sport participation (Aspen Institute, 2015), and little research has been done on the impact this route will have on family functioning. While there is support that positive outcomes are associated with both family play and participation in organized sport, it is unclear what conditions are beneficial or hurtful for 
family functioning especially in elite youth sport.

The purpose of this study is to understand the relationship between elite youth sport participation and the family system. More specifically, we intend to answer RQ1: "How is participation in elite youth sport impacting families?" And RQ2: "What league characteristics facilitate or impede family functioning?" In doing so, this study contributes to the sport management literature by examining how youth sport implementation impacts families. The findings from this study can provide information to families about how to successfully navigate the youth elite sport experience. It also provides sport managers with knowledge that can improve the design and implementation of their sport programs such that participants and their families benefit from greater family functioning, ultimately resulting in sustained and perhaps healthier life-long sport participation (cf. Berg, Warner, \& Das, 2014; Lim et al., 2011).

\section{Theoretical Framework: Family Systems Theory}

Given the complex nature of families and the variety of interactions that occur within a family, it makes sense to view a family as an entire system as opposed to a collection of individual parts (Becvar \& Becvar, 2000; Olson, 2000). Parsons (1951) noted that the components of a family must include diffuse social interactions, particularistic rules, affective relationships, and ascribed relationships. In other words, a family must have a variety of interactions that span a variety of situations, have flexible rules that apply to different members based on their familial role, have an expression of personal feelings and emotions and finally have status

independently of others within the family. Consequently, studying the family members individually and combining the data will not present a complete picture of the family, as the whole family is greater than the sum of its members (Olson, 2000).

The key to understanding a system as a whole is to focus on the interrelations between parts of the system. In the case of the family, the interrelations between parts refer to the interactions between family members. Bronfenbrenner's $(1995,2005)$ Process-Person-Context-Time (PPCT) model, is one of several important family systems theoretical models. It examines how human development is influenced by the environment in which the person exists and also the interactions that occur within that environment. These interactions are referred to as proximal processes and operate over time. For example, if a decision is going to be made as to a sport in which to enroll a child, multiple interactions within the family will take place. The child might suggest some sports in which he or she is interested and discuss those with one or both of the parents. The parents might discuss with each other what sport and league they feel is most appropriate for their child. These interactions may occur 
regularly and may change in content and outcome over time and can also have an impact on the development of both the parents and the child.

Such relationships and negotiations are also reciprocal—going from parent to child, and child to parent, and inside and outside the family. Sport scholars have also highlighted these reciprocal relationships among athletes and parents (Dorsch et al., 2009, 2015; Holt, Tamminen, Black, Mandigo, \& Fox, 2009). The reciprocal nature of relationships in the family and how, in the larger context, they work towards homeostasis within the family is paramount to understanding family functioning (Cox \& Paley, 1997). Just because the relationships are reciprocal does not imply that they are random. In fact, a number of scholars suggest they are arranged hierarchically (e.g., Broderick, 1993; Cox \& Paley, 1997; 2003). The hierarchical nature of families is defined by the boundaries that exist between the subsystems. In a family, the dominant subsystems are the marital, parent-child, and sibling subsystems. The boundaries between subsystems help establish roles and maintain family rules (Minuchin, 1985). In families with rigid boundaries, the hierarchy is stronger and more authoritative in nature, while families with flexible boundaries are more democratic and children have more input.

Prior research has shown a positive relationship between subsystems and individual development. For example, a positive linear relationship has been shown between the parent-child subsystem and individual development. In addition, a positive linear relationship between the parent-child subsystem and marital subsystem has been supported in the literature (Cox \& Paley, 1997; 2003). Individuals in the family are affected by the ongoing patterns that take place within the family (Minuchin, 1985; Olson, 2000). Development refers to both the behavioral change as well as the intellectual growth of individuals in the family (Minuchin, 1985). While development sounds as if it refers only to positive growth, Bronfenbrenner (1992) pointed out that the core of development is a change within the individual that can either be positive or negative.

While the majority of research on the family has focused on individuals and the subsystems that are composed of dyads, family therapists and family systems theory have noted the importance of expanding the research focus to triads and larger family units (Cox \& Paley, 1997; 2003; Olson, 2000). Thus, a family systems perspective will be utilized to better understand the impact of youth sport on families.

\section{Organized Sport and the Family}

Both parental and sibling input have been found to impact the athlete experience. Research supports that parents who do not place pressure on their children to be successful, but remained supportive, are more likely to have engaged athletes 
(Dixon et al., 2008; Fraser-Thomas, Côté, \& Deakin, 2008). Conversely, parents who attempt to coach their children, offer incentives for winning, and/or pressure them to remain on the team are more likely to cause their child to drop out (FraserThomas et al., 2008). Siblings also play a significant role in the athlete's experience. Athlete engagement is enhanced if the sibling is supportive and does not engage in rivalries or jealousy (Blazo, Czech, Carson, \& Dees, 2014; Fraser-Thomas et al., 2008).

In addition to variation in how both parents and siblings engage with the athlete, scholars have also examined the relationship between the family as a unit and sport participation choices and experiences. Côté (1999) found that families play important roles in terms of socialization and financial, time, and emotional support for children as they progress in sport. These roles shift throughout the developmental model of sport participation, moving from serving as the socializing agent to predominantly providing time and financial commitment. Typically, the family's first role in youth sport participation is through socializing the child into a sport league, and providing numerous sporting opportunities for the child. Dixon et al. (2008) and Coakley (1987) specifically stated that parents who are former athletes themselves are more likely to initiate the socialization process of their children into sport. Beyond influencing children into beginning their sport involvement, parents also socialize children towards their sport achievement orientation and influence whether or not elite sport is pursued (Kay, 2000).

Wiersma and Fifer (2008) found that beyond the initial introduction and socialization, parents in particular also provide instrumental support (transportation, financial resources, etc.). One of the various demands that organized sport has on the family is consumption of resources (Dixon et al., 2008; Kay, 2000). In a study on elite athletes, Kay (2000) found that the financial commitment to participate in high-level sport was cited as the biggest issue for families. This financial burden of participation was also found to be substantial in other studies related to youth sport and family (e.g., Dixon et al., 2008; Hellstedt, 1995).

Beyond financial commitment, families noted a large time commitment to youth sport. Kay (2000) refers to this time commitment as an alteration in family activity patterns. In her study, parents noted that the sport time demands affected their daily schedule and caused changes to vacation plans and work hours. One parent even noted he would sleep in his car after dropping his child off at swim practice to gain additional sleep before starting the workday. The large amount of time required to provide opportunities for deliberate practice for their children is crucial for skill development and clearly alters family activity patterns and schedules (Ericcson, Krampe, \& Tesch-Romer, 1993). Thompson's (1999) work further supported this notion, as the mothers of elite tennis 
players she interviewed needed a large time commitment just to drive their children to tournaments and practice, usually sacrificing their own opportunities for sport participation.

In addition to providing instrumental support in the form of time and finances, families also provide emotional support to participants (O'Rourke, Smith, Smoll, \& Cumming, 2014; Wiersma \& Fifer, 2008). The emotional resources provided by the family are crucial for the athlete's well-being and continuation in sport. Whether it be a post-game talk, providing motivation, or helping the child to maintain a balance between competition and fun, emotional support is crucial for maintaining a positive experience for the participant (Dixon et al., 2008; Warner et al., 2015; Wiersma \& Fifer, 2008). Kay (2000) found that families typically believe that providing emotional support is also necessary for talent development. Many of the athletes that she interviewed stressed that without emotional support from their family, they would be unmotivated and unlikely to continue in the sport.

\section{Sport and Family Outcomes}

With the variety of roles the family plays, it is important to understand the different outcomes for both individuals and families related to the sport experience. Individual sport-related outcomes for family members may be positive or negative. Potential positive benefits for the participant may include talent growth, an increase in self-esteem, or the development of persistence (Fraser-Thomas, Côté, \& Deakin, 2005). Negative impacts may include an increase in stress and anxiety (O’Rourke et al., 2011) along with a decrease in self-esteem or injury (FraserThomas et al., 2008; Kay, 2000). Kay (2000) found that some athletes experienced emotional highs and lows that were directly related to their performance in their athletic event. In some instances, athletes undergo high levels of stress, due to parental and coach pressure; they often suffer from burnout and cease participation (FraserThomas et al., 2008). Other athletes suffer injury from too much participation and some studies have shown as high as 21.5 percent of athletes were asked to participate while injured (Engh, 1999).

While much work has focused on the inputs and outcomes for sport participants, much less attention has been given to the impact of sport on other family members and the family itself (see also Warner et al., 2015). For other individuals in the family, positive benefits may include an increased sense of pride for the participant's experience or the addition of more instances of socialization with other individuals. For example, Kay (2000) found that some parents felt a greater sense of pride when their child was successful on the field or court. Dorsch et al. (2009) found that sport can be a powerful vehicle for parent socialization. As parents became more socialized into sport, they began to use the sport context to improve 
communication, teach life lessons, and enhance their own development as a parent (Dorsch et al., 2015). Negative impacts may include feelings of jealousy, resentment, or a lack of time for other activities (Côté, 1999). Siblings have reported negative impacts of their brother or sister participating. Kay (2000) found that some siblings who did not participate felt jealousy toward the athlete and felt their relationships with their parents were not as strong as the relationship between the athlete and parents. Finally, parents have been shown to engage in lower levels of physical activity as a result of their children's participation (Dixon, 2009; Thompson, 1999).

In addition to positive or negative outcomes for individual family members, it is plausible that the family unit may also experience positive or negative outcomes. A few studies have indicated the potential positive outcomes for families, which include an increase in family closeness or improved family communication (Zabriskie $\&$ McCormick, 2001). Potential negative family impacts include feelings of jealousy or resentment, depletion of resources, or a conflict of family values with the values of the sport league (Côté, 1999). For example, mothers in Thompson's (1999) study cited that their entire family suffered burnout-like symptoms from the time demands placed on the family to foster participation in youth sport for one family member.

In summation, researchers have examined the relationship of sport and families, yet the majority of these studies have examined the unidirectional relationship of the family to sport, particularly how families can better support the high performance sport participation of children (cf. Green \& Chalip, 1997; Hasbrook, 1986; Kay, 2000). The current literature base illuminates a few of the ways that individual family members and the family unit may be impacted by youth sport in general, but does not necessarily identify the components of the sport experience that lead to positive or negative outcomes.

Given the initial work in elite youth sport by Kay (2000) and Thompson (1999), it appears that elite youth sport participation may have strong and lasting influence on family members and family systems. As youth sport in the U.S. trends towards more elite, travel-based teams with a focus on skill development, and away from more playful, leisure-type activities (see Aspen Institute, 2015), it is crucial to understand what impact (both positive and negative) these particular contexts have on families and how leagues might foster more positive outcomes for families.

\section{Method}

A multiple case study approach was utilized as this study thoroughly examined multiple families in regards to a specific social phenomenon, elite sport participation. Further, the cases were used in constant comparison within and between families to gain insight into how this social experience is impacting family functioning. Similarly to Dorsch and colleagues (2015), a 
social constructivist epistemology was used to frame the study. This epistemologically standpoint and multiple case study approach were appropriate for gaining in-depth insight and knowledge into a specific social phenomenon.

From a practical perspective, Eisenhardt (1989) provided a step-by-step guide for conducting a multi-case study. This study of multiple families fit neatly in her practical framework. Using the multiple case approach (Thomas, 2011), we utilized both inductive and deductive reasoning to guide our coding and analysis. Constructs based on family systems theory were initially identified a priori in an attempt to provide more empirical grounding for the emerging theory. Then, utilizing procedures that Glaser and Strauss (1967) suggest, the data were continuously compared and analyzed until themes began to emerge. Thus, both deductive and inductive processes were utilized — with an eye toward family systems theory, yet openness to the emergence of new experiences and codes, especially those that were specific to sport.

Specifically, this study utilized multiple family cases to examine the major elements of the sport experience that impact family functioning. The themes that emerged within families were compared with and across families (Eisenhardt, 1989). This type of comparative case-based research has the ability to simultaneously examine multiple facets of data to provide a holistic view of a complex situation (Glaser \& Strauss, 1967).
One underlying assumption within the study was that participation in extracurricular activities would introduce stressors into the family unit. Further, various aspects of family structure, and the nature of the activity, all play a role in the overall impact of the activity. As a population was identified to study, the authors identified a specific population elite youth sport participants - that would introduce higher amounts of stressors to the family system.

Eisenhardt (1989) noted that the concept of population is crucial in case study research, as it has an effect on controlling variance and the generalizability of the study. The authors note that there are many sport and family variables that impact family functioning. Considering the purpose of this study was to understand the impact of participating in elite youth sport on the family unit, purposeful sampling was used to identify families involved with elite youth sport. There are seemingly endless combinations of family types and structures (Broderick, 1993). Attempting to cover all of them would be nearly impossible and would lead to so much variance in the family make-up itself that the relevant family variables to the study could not emerge. Thus, variables such as family size and composition, socioeconomic status, and sport experience were controlled for through purposeful sampling as both family variables and sport variables may impact family functioning. Family parameters were limited to those that have two married 
parents at home with at least two children. These parameters were set because families participating in an elite travel-based league and who have multiple children with whom to negotiate schedules and resources are most likely to experience stress that will impact family interactions and possibly family well-being.

\section{Procedure and Participants}

Once families were identified through purposeful sampling and gave verbal consent, interviews were scheduled at the family home. Upon arrival in the home, participants signed an Institutional Review Board approved informed consent form. Data were then collected through semistructured, in-person, one-on-one interviews with each family member. Interviews were semi-structured, but followed an open-ended interview guide targeted to gaining insights into how the family functioning was affected by participation in the youth sport league. Interview guide questions were derived from Orlick's (1974) interview schedule designed to assess family sports environment and from the McMaster Family Assessment Device (Epstein, Bishop, \& Levin, 1978). Sample interview guide questions included, "Tell me about the decision you made to initially get your child involved in sport"; "Tell me about your role with the team and what that entails" and "Tell me about a great/worst experience you had with your team". Interviews lasted between 45 minutes and one hour with each family member. Interviews were audio recorded and field notes were taken.

Seven families, with a total of 31 participants, took part in interviews (see Table 1). All parents in the study were married at least 10 years, and had children ranging from 8-18 years old.

\section{Data Analysis}

Interviews were transcribed and then the primary researcher used semi-closed coding to code the data line-by-line. That is, in the first iteration, themes such as communication, resources, impact on marital dyad, and family structure that are based in family systems theory were coded in the data. Then, in the second iteration, the primary researcher examined the data for emergent codes - examples of such codes include league supports, expectations, and scheduling.

Then, the similarities and differences in the data were compared (i.e., constant comparison) to generate a coding scheme and final codes (Glaser, 1978). Codes were then clustered into categories. This process continued with the influx of new data until data saturation occurred, the point when no new categories were generated from the codes. Categories are compared to one another and the relationships and integration of categories form the basis for the emergent theory (Glaser, 1978). Data collection and analysis continued until saturation occurred and the benefit of adding new cases was outweighed by the 
contribution that each new case would add (Glaser \& Strauss, 1967). This method of coding was used to allow the researchers to gather rich data that was informed by prior cases. This allowed categories that were identified early in the study to be further examined.

Once data were all coded, the next step of data analysis in the comparative case method was within-case analysis. Data from each case study was written up as a stand-alone entity (Eisenhardt, 1989). By focusing on each case individually, unique patterns were allowed to emerge from within each case. Next, between-case comparisons were conducted. This entailed analyzing for within-group similarities and intergroup differences. At this point, no new themes were emerging, the researchers were garnering a sense of the themes' meanings and how they fit together. Thus, all three researchers independently compared the cases in order to provide more focus for intergroup analysis (Eisenhardt, 1989).

The final stage of analysis was to compare across the cases. This was undertaken by all three researchers. The overall goal of between case comparisons is to move past simple first impressions of the data and to increase the likelihood of generating novel insight. Through this iterative process, the code categories that emerged were condensed into themes that best represented the participant families' experiences within elite youth sport.

\section{Results}

After interviewing seven families, the results revealed there were some commonalities across the families in terms of the challenges and supports that positively or negatively impact their family functioning. First, the overview of challenges for martial dyad and family unit will be provided (RQ1: "How is participation in elite youth sport impacting families?") and then the specific league characteristics will be highlighted (RQ2: "What league characteristics facilitate or impede family functioning?”).

\section{Challenges: Impact of Youth Sport on Families}

\section{Depletion of Resources}

The main challenge that all families incurred as a result of their participation in youth sport was the incredible demand on time and financial resources. While reduced family time was evident across all families, the consumption of financial resources had a larger strain on the families with the lowest income in the sample (Family 3 and 6). The results indicated this Depletion of Resources impacted both the martial dyad and family unit.

Martial Dyad Impact. All of the families in this study had parents who were married for over 10 years. This was probably a source of strength in that the marriages seemed to be seasoned and relatively stable. However, children's participation in elite sport placed tremendous strain on the marital dyad due 
to the Depletion of Resources. Elite sport consumed a lot of resources (e.g., money, time, emotional and physical energy), reducing the amount that could have otherwise been spent on the marital dyad. The mother in Family 1 said that she and her husband's conversations typically consisted of working out logistics for the children. She said, "Our conversations go something like, 'What are you doing? Where are you going? When are you going to be here?' You know, typical kind of coordination type stuff." Speaking to what she and her husband regularly discuss, the mother of Family 6 said:

Sometimes we don't even talk. He's at the field picking them up at 10:00 p.m. There are some weeks it feels they have practice after school five days a week and he is either in the car or at the field. The father from Family 6, when asked about spending time with his wife said, 'Yeah, but that doesn't come with having kids. You can make some time, but before they start driving, the only way she is going to get there is by you driving her [the daughter]." Family 3 also noted issues with time dedicated to the marital dyad. The mother said, "I think it goes back to the sacrifice area. Honestly, pretty much every night of the week is involved with sport or sporting events. I think it's something we neglect. Taking time for just the two of us." The father from Family 3 added, "Between our kids and my job, there's usually not a lot of time to spend together."
Overall it was clear that the martial dyads in these families were experiencing stress and a severe lack of quality communication as a result of a child participating in elite youth sport. This stress was attributed to the time commitment of sport that was interfering with overall quality interactions with spouses. Despite this added stress, most parents accepted this as part of having a child athlete. To them, the opportunity provided to their child to play sport warranted the sacrifice they were making.

Family unit impact. Another result of Depletion of Resources in the elite youth sport experience was a strain on the family unit, especially considering the participating families had multiple children. With conflicting activities from other children, parents and children often noted how they would divide the family to accomplish their tasks for the day. This seemed to have a negative impact on functioning, potentially impacting cohesion and reducing the amount of time spent together. For example, Family 2 often split up on the weekends in order to accommodate the schedules of their children's activities. The father said, "With three kids, we have often overlapping activities." The oldest daughter in Family 2 mentioned how she wished more people from her family could come to her concerts. She added, "Most of the time, we don't have time to do other things because I'm always in a concert or my brother or sister have a game. It'd be fun if we had more time together." 
The youngest daughter of Family 6 expressed a desire to spend more time together as a family and said that she "hates" attending practice and soccer games. She summarized simply, "It makes me angry." Family 3 gave priority to the older sibling in terms of extracurricular activities. The father noted, "I will not let my son play for certain baseball teams due to their practice schedule. We tell him we want him to try everything, but we don't want the two sports to overlap too much." While it is important to maintain a schedule that works for the family, giving priority to one's activities over another may impact the relationships within the family.

Family 4 further highlighted the problem with time demands. The youngest son was not only resentful that he was unable to freely choose his extracurricular activities, but also expressed a desire to spend more time as a family together. Family 5, in perhaps an extreme example, was living two hours apart so the son could attend a hockey academy. All four family members expressed a desire to spend more time together, but noted that it was "just a sacrifice" that comes with participation in the academy.

Family 3 was negatively impacted by Depletion of Resources, but in this case it was in terms of both financial strain and time spent together. The father said:

Financially, it's a struggle. Sometimes we do without other things to meet the cost. I tell my daughter, and I don't think she takes me serious, but I've wanted a 24-foot boat and I'm like, 'I want you to know that instead of me getting my boat, I'm investing my money in you: our travel, our plane tickets, fuel, upkeep of cars, food, lodging and extra training. This not only put a financial sacrifice on the family, but it also placed additional stress on the daughter as she overtly understood the family was making trade-offs for her benefit. Family 6 also felt the Depletion of Resources in terms of financial strain negatively impacting the family unit. The father of Family 6 said, "There are certain things you can't do because of the cost and because every weekend she's tied up. It makes it hard to visit relatives or take vacation." Both children mentioned a desire to take more family vacations and the youngest daughter expressed an interest to even see more movies as a family. Like some of the other stressors associated with sport participation, Family 4 felt this was a necessary sacrifice. The mother said, "It's definitely a sacrifice, but when your kids love it that much you do what you have to do."

One family, however, was an exception. They perceived that elite youth sport participation demanded resources in a positive way. This family, Family 7 , had all three children enrolled in the same club. The mother said:

It has impacted our family very much. I don't know, most of what we do is being in the pool and going to meets. We never said our kids had to be 
involved, but once you are there for so long you might as well get in the water and get some exercise. Swimming is part of our family. It has been very positive.

Even in the rare case when only one child had a meet, other members made an attempt to attend. The oldest son said, "Like yesterday, I went to her practice and then she went straight to a meet and we watched her swim." Their sport time, most likely because they were in the same sport at the same club, was spent together as a family, potentially increasing their cohesion and functioning.

The trade-offs and sacrifices needed to participate in elite youth sport appear to generally have a negative impact on family functioning, particularly in the marital dyad. Families that intentionally pursue sports for the whole family may be the exception. Still, this family did not suggest that sport did not place a strong demand, but simply that the resources (time and money) were well spent and perhaps mutually beneficial.

\section{League/Sport Support of Families}

The data also revealed specific league or sport club characteristics or supports that also impacted the family and family functioning (RQ2). Interestingly, coaching input, scheduling, league expectations, and instrumental support were found to be key themes when the participants discussed league supports and family functioning.

Coaching Input. One situation that had a positive impact on family participation, and thus may have impacted family functioning positively, was parental input on coaching decisions. Family 1 had direct input, in the form of interviewing potential candidates to serve as their child's elite head coach. This family noted that the coach that they helped choose shared their same values and, as a result, the family had an overall positive relationship with the coach even in the face of adversity. The mother stated, "I liked [our coach] for a lot of reasons. I had heard about him and got [my son] where he needed to be so he could be on that team...He's a Christian man. He teaches the boys about baseball, but he also taught them how to be good people." It is likely that these positive feelings, both from the athlete and the parents, increased family functioning. Family 5 did not have direct input in their son's coach, but had the opportunity to meet him and were able to establish a sense of his values prior to enrollment. This enabled them to be sure that he shared similar values to their family and that he would be a good coach, not only for their son, but for the parents as well.

The families whose sport teams did not allow for parents to have a say in the coach or even the ability to interview a coach ahead of time noted some difficulties. Families often switched clubs or noted that the experience for their child was negative. The father from Family 2 said, "Once you get a professional coach, I think there should be some feedback because those leagues are not cheap. It would be good to have a feedback loop for the parents to tell 
people if they like the coaches." Family 4 noted difficulties with the entire process of their daughter being selected to a team. The father said:

I wish I knew how they made their trooper decisions or how they say this person will be on this team and this person will not be on this team. I don't think it's necessarily the skill all the time. I think a lot of that is being who you are or how you present your kid. I just want it to be fair all along the process.

If a family does not have say in the coach, they do not have the ability to select a coach that is a good fit with the family. If a family is able to select a coach that has shared values and goals, like in Family 1 and Family 5 , they can advocate for a specific coach that will provide appropriate development for their child and be perceived as fair. In cases in which the family has no voice in the coach, there were feelings of resentment and a perceived lack of trust. Most parents justified wanting input on the coach due to the high cost of the league. They wanted to see a perceived value for the salary the coach requires. Overall it was clear, for both the athlete and the parents, coaching imput impacted the individuals in the family system and lack of it reduced functioning.

Scheduling. Another way that the clubs structured their leagues that impacted the family was through inconsistent scheduling and schedule changes. The mother in Family 1 summarized difficulties of schedule changes, "[The coach] would change the practices.... .Yes it's a time commitment... [but] I have to have some kind of continuity in what's going on." When leagues were consistent with their scheduling, families were able to make necessary adjustments to provide appropriate instrumental support. This removes some of the stress present in the family system and also increases their problem solving ability; thus, positively impact functioning. Family 7, despite living in separate cities, noted increased levels of cohesion and communication as a result of clear scheduling. The hockey academy demanded a large amount of time, but had a consistent schedule that was set and easier to plan for and manage. The father noted: The team provides a bus that picks him at school and takes him to practice. And, he's at practice from 2:00pm until 6:00pm. Our apartment is about five minutes away from the rink. So, I usually wrap up my work-day about 5:30 pm, and then drive over and pick him up from the rink. We come home, and have dinner, and he does his homework. And, because of that, he has a lot more time, to focus on things that he needs to focus on. Not spending so much time in the car is a big part of that.

Family 7 suggested this consistency in scheduling positively impacted their family functioning. Conversely, families without this type of firm schedule found scheduling to negatively impact their family functioning. Family 1 noted that their team was sporadic 
with its scheduling, the team frequently gave short notice of practice time changes, and it became difficult to coordinate everyone's schedule. The mother added:

When we first joined on with him he would change the practices. I'd say, 'Are you joking with me? [My son] is not my only child! Baseball is not my only thing. ... You can't do that to me. By changing schedules and not considering families scheduling needs, the league is likely negatively impacting family functioning.

Expectations. League expectations also may impact family functioning. Most of the families in this study talked about a change in expectations when their elite athlete went from recreational sport to elite sport. In addition to an increase in practice time and in events, there was a level of expectation that attendance was mandatory. With recreational leagues and even high school teams, families talked about how they could miss practice if something important to their family came up. When the children were enrolled on the elite team, missing a practice was not an option. The mother from Family 1 commented on the expectations in elite sport:

I think the expectations change. They expect your son to perform at all times. Whereas daddy coach [volunteer coach], it's fine! I expect the daddy coach to do good for my son, whereas the paid coach expects my son to perform. It's kind of switched.

She commented that her coach offered optional clinics each week, but felt that there was an expectation for her son to attend all of those clinics. Reflecting on recreational sport, the father from Family 4 talked about a great team his oldest daughter played for "before politics and everything got involved like in select soccer or select sport." The mother in Family 6 added:

Until last year [our oldest daughter] never missed a practice. I mean, at one point, she had broke her toe on the field. She played on it and it got infected. It ended with her being in the hospital for a week, but she didn't miss any practice because they were rained out that week.

The ramifications of missing practice or games included upsetting the coach, missing out on skill development opportunities, or not getting playing time solely based on the fact that practice was missed. This additional pressure seemed to cause families to reprioritize activities within their family and in some cases eliminate certain activities. For example, the son in Family 2 was only allowed to participate in sports that were not in conflict with his sister's elite soccer. Due to the league expectations, the parents in Family 2 were forced to prioritize their children's sport opportunities and this impacted family functioning.

The leagues' expectations regarding the structure and manner in which leagues inform parents of additional costs also seemed to impact the family unit. Families 3,5 , and 7 were all members of leagues that were clear and candid with the cost of their 
services and did not overburden families with additional clinics or extra services. In these instances, families still thought the prices were high, but were able to make informed decisions about enrolling. This allowed them to appropriately plan for the cost of the league and alleviate the stress of surprises. The father from Family 2 said:

I was really shocked at the price when I first looked at it. First of all, being from France, I was not used to seeing people spend that much money on sports. So to me it seems excessive. I mean, it's nice having all of the matching gear and being part of a team, but it's a little bit overboard. I know there is some assistance to enable people who don't have the means to join, but there are some people that probably don't participate because they just can't afford it. I think that's too bad.

The other families were involved with leagues that offered additional clinics and provided supplemental services such as recruitment packages. In these leagues, families were not as able to plan for the costs associated and often felt pressure to partake in these services as the league was not upfront about their expectations. The mother from Family 4 said, "And there are other fees that just come up for stuff. Like [for my oldest daughter], there are like recruiting aides that we have to buy." She estimated it cost $\$ 200$ and noted that there was pressure to purchase the recruiting aid from the league, and peer pressure to get the same thing for her daughter that her teammates were getting. The mother from Family 1 spoke about optional clinics that her son was expected to attend and said, "[The coach] called it optional. [My son] would participate in one of them on Tuesday or Thursday for an hour and half. We paid extra for those." The overall financial expectations, along with making decisions that were not fiscally sound or partaking in extra activities due to pressure that resulted from expectations not being clearly explained, contributed negatively to family functioning.

Instrumental Support. One of the most salient ways that the leagues helped support families was through reducing the amount of instrumental support provided by the parents. Interestingly, Families 5 and 7 had unique situations that enabled the families to significantly reduce the amount of instrumental support they provided on their own. In the case of Family 5, the hockey academy handled almost all of the transportation. Transportation to and from practice was provided during the week and was included for some games. The father who was living near the academy with his son was able to attend some of his son's practices with ease and did not have to worry about coordinating any logistics during the week. He said, "You know, it's relieved a lot of stress in our relationship. Just in regards of 'who's getting him to practice today?' and 'who's going to be able to take him to his game on the weekend?"'

Multiple families in this study talked about how they required carpools to 
provide assistance in cases of scheduling difficulties. One parent suggested that leagues could offer tools online that would enable parents to connect with one another to provide services like carpools. Another example of reducing this instrumental support was found in Family 7's swim club. Family 7 still coordinated travel during the week and noted some stress with transportation, but all three children practiced at the same facility. The father said, "The little one doesn't swim in the meets, he is just learning competitive swimming, but the other two swim at the same time. Seventyfive percent of the time we are all there." Not only did this eliminate the need for carpooling and additional support to facilitate practice, it provided an opportunity for the children to complete their homework prior to arriving home for the night. In both Family 5 and 7's situations, the families were able to reduce the amount of time dealing with situations that occurred outside of the family unit, allowing them to focus on the family more when they were together, positively benefitting family functioning. Overall, it was clear that instrumental support could positively impact family functioning within elite youth sport settings.

\section{Summary}

The results point to how both the martial dyad and family unit are impacted by their child's participation in elite youth sport, specifically through the Depletion of Resources. The main way that marriages and families support functioning is through spending time together, and the youth sport experience in most instances creates a challenge to do this. Families that make a specific effort to spend time together as a family are able to better focus on the individuals that make up the family. This focus on all the members collectively should improve family intimacy, communication, and ultimately functioning.

The results clearly indicate the challenge that the youth sport experience provides, due the time commitment and logistics, for both the marriage and family unit. The results also highlight the specific sport league factors that also are impacting family functioning. Specifically, the family's role in coaching input, league scheduling, league expectations, and instrumental support are key, and perhaps overlooked factors that are impacting family functioning.

\section{Discussion}

This study sought to better understand the relationship between elite youth sport participation and the family system. After interviewing seven families, the results highlighted how the Depletion of Resources and specific league factors (i.e., coaching input, league scheduling, league expectations, and instrumental support) were impacting the families interviewed. Previous research noted that the financial burden was a large stressor on families enrolled in select clubs (Dixon et al., 2008; Hellstedt, 1995; Kay, 2000). In fact, Kay (2000), in a series of interviews with a large number of families, 
found that cost was the biggest burden placed on families with elite sport participants. In this study, cost was noted as a concern, especially for Families 3 and 6, but it was not a concern that seemed to impact the families on a daily basis. It should be noted that the families interviewed had sufficient resources, and the number of elite team participation opportunities for them to participate in have increased overall. Thus, this increase may have resulted in parents being more accepting of the costs incurred.

While it appeared that cost was not a huge barrier in this study, the participants did note sacrifices they made in order to play_including foregoing material possessions and even relocating the family. It is not clear, therefore, how individual family members ascribe a value to "financial resources" and when they see the cost as "worth it" or not. Future research should explore the threshold elite sports have in terms of cost and explore patterns of dropout as they relate to family financial resources.

Rather than cost, families in this study consistently cited the depletion of time as the biggest challenge impacting their families. The time spent transporting and coordinating travel appeared to have the largest impact on overall family functioning as it strained the martial dyad. This finding is important because, while the families may not agree with the cost, they accept it and make sacrifices to accommodate it. Families that had to spend a great deal of their time coordinating schedules and transportation appeared to have greater levels of stress surrounding sport, less time to spend as a family outside of sport, and less quality time to focus on the marital dyad and family unit. Family systems theory literature supports the notion that these ongoing patterns of behavior will impact family functioning (Brofenbrenner, 1992; Minuchin, 1985; Olsen, 2000). The parents in this study seemed to dismiss any issues associated with stress as part of having an elite child athlete. Dorsch et al. (2015) found many benefits of parents' socialization into sport, but this might suggest that it could lead to the acceptance of unnecessary stress (in terms of time and financial resources). Despite severely restricting time together, restricting the level of communication, and limiting the ability to participate in other activities, parents accepted the sacrifices and never seemed to question why they were making them.

Future research should continue to explore the family time that is sacrificed for elite youth sports and the assumption that this is necessary to provide opportunity to elite athletes. This would be helpful in terms of building the work of Dorsch and colleagues $(2009,2015)$ regarding both the processes and outcomes of parental socialization into sport. It would be beneficial to better understand when and how sport participants and families come to understand "what it takes" to be an elite participant, and even more importantly, 
how they come to accept those sacrifices as "normal."

One of the big differences between the financial strain and the time strain that sport places on the family is that time stress impacts the family on a daily basis in a palatable way. In addition to dividing families, the time demands of transportation limited the extracurricular activities for all other members of the family, with the nonparticipant being impacted the most. The ability of a family to cope with these demands is likely linked to the flexibility between subsystem boundaries (Broderick, 1993; Cox \& Paley, 1997). A greater priority was given to the elite league, and often siblings had to structure and select their activities in a manner that avoided conflict with the elite league. This led to some cases of the sibling feeling resentment towards the athlete and feeling restricted as to what activities they can select from. Côté (1999) found that siblings play a significant role in supporting youth athletes. If family decisions are negatively impacting the sibling, it is likely to negatively impact the athlete as well. Cox and Paley (1997) note that the reciprocal nature of family relationships is crucial in reaching homeostasis. Future research should focus on the non-participant sibling and the impact this individual has on family functioning.

Another difference between cost and time is the issue of predictability. The cost is typically known ahead of time and families can plan for the predicted costs, but the schedule often changes throughout the season, making it harder to plan for. Some of the families in this study were faced with unpredictable schedules that required problem solving and unplanned alterations to their schedule. Unpredictability causes additional strain on family communications and resources. Fraser-Thomas et al. (2005) found that parental influence has an impact on whether or not the experience is positive for the child. When the program is able to make changes without parental input, it is more likely to introduce additional stress and negatively impact the family. The proximal processes that would be taking place in this environment would likely be negative and thus impact the family unit (Brofenbrenner, 1999, 2005). Thus, sport leagues that are up-front and predictable in terms of cost and scheduling vastly reduce the stress and strain on family functioning. As demonstrated by Family 4's experience, the inclusive, predictable sport structure severely reduced the amount of instrumental support that was required by the family to facilitate the athlete's participation in the elite hockey academy. The sport league taking on this instrumental support (e.g., transportation) that is traditionally provided by the family allowed the family to focus on other members and other assets of their lives outside of sport. Similar findings were observed in Family 7 in that they required less time outside of sport spent on instrumental support because all of the children participated in swimming at the same facility. Despite 
three children engaged in three different levels of swimming, the family did not have to split up and send individuals to different facilities in order to accommodate the schedule demands of the sport. An area of future research could compare the family experience in private leagues and those that are organized by parents.

While not everyone will be able to afford or want to send their children to a sport academy or enroll them in the same sport, there are some lessons to be gained especially for sport managers. Sport managers can learn ways that they can ease some of the burden placed on the family. The results suggest that this can be accomplished by understanding the impact that coaching input, league scheduling, expectations, and instrumental support are having on family functioning. For example, sport leagues could provide transportation to/from practice, allow parents more of a voice in scheduling and coaching decisions, and attempt to schedule facilities that are central to their participants. If leagues were able to assist parents in transportation, it would not only alleviate a large source of stress and time demanded from the family, but it would also allow the league to schedule in a way that benefits the league and the families involved. Leagues would not have to cater to the work schedules of the parents if the league's employees were providing transportation to the athletes. If a league is unable to provide this additional service, allowing the parents to have more of a voice in scheduling could increase the level of engagement of the parents and help the league develop a schedule that would best suit its participants. Granting the parents a voice in coaching decisions might also dually increase the level of engagement between the parents and the league while helping ensure that the majority of the parents are satisfied with the individual who is a coach of their child(ren). Finally, leagues could ease some of the transportation cost to the families by selecting families that are closely located to their facilities. This would not only aid in families being able to carpool, but it would cut down on the total transportation time on the family in order to facilitate transportation. This would decrease the time demands placed on the family.

Families can also better educate themselves about the financial and time commitment that it actually takes to participate in an elite sport league. If families are able to plan ahead for the time demands and the financial demands of the sport, they can select a league that is the best fit for their family. This would also reduce the strain put towards problem solving and ease the total stress placed on the family from elite youth sport participation. Ultimately, this would positively impact family functioning.

Overall, the results point to the impact elite sport has on family functioning, and, in doing so, highlights the challenges that elite sport families face. In an effort to positively contribute to family function, sport administrators should consider the 
knowledge gleaned from these results. The results also offer insight into the challenges that parents must learn to navigate in such a way that elite sport does not detract from family functioning.

\section{Future Research}

Future research on family functioning and sport should examine the relationship between instrumental support and functioning with a greater variety of sport structures (e.g., recreation, school-based). Such structures could include leagues with central facilities, localized facilities, and leagues that provide transportation to and from practice. This study and its findings are limited to the experience of seven families involved in elite youth sport, and therefore future work should consider both including more families and also following these families over the course of a longer time span. In addition, future research should focus more thoroughly on the nonparticipant sibling. While this study gained some insights from the siblings, the nature of the research did not afford as much depth as preferred. Finally, future studies should try to gain a greater understanding of family functioning throughout the athletic season. A study that covered a family from pre-season, season, and post-season could better highlight specific incidents and document first-hand the impact they had on the family. 


\section{References}

Aspen Institute (2015). Play for Life: A

Playbook to Get Every Kid in the Game.

Retrieved from

http:/ / aspenprojectplay.org/sites/de fault/files/Aspen $\% 20$ Institute $\% 20 \mathrm{Pr}$ oject $\% 20$ Play $\% 20$ Report.pdf

Bebiroglu, G., Geldhof, G. J., Pinderhughes, E. E., Phelps, E., \& Lerner, R. M. (2013). From family to society: The role of perceived parenting behaviors in promoting youth civic engagement. Parenting, Science, and Practice. 13, 153-168.

Becvar, D.S. \& Becvar, R.J. (2000). Family therapy: A systemic integration ( $4^{\text {th }} \mathrm{ed}$.). Boston: Allyn \& Bacon.

Berg, B., Warner, S., \& Das, B. (2014). What about sport? A public health perspective. Sport Management Review. DOI:10.1016/j.smr.2014.09.005

Blazo, J. A., Czech, D. R., Carson, S., \& Dees, W. (2014). A qualitative investigation of the sibling sport achievement experience. Sport Psychologist, 28(1), 36-47. DOI: 10.1123/tsp.2012-0089

Bronfenbrenner, U. (1992). Ecological systems theory. In R. Vasta (Ed.), Six theories of child development: Revised formulations and current issues (pp. 187249). London: Jessica Kingsley.

Bronfenbrenner, U. (1995). Developmental ecology through space and time: A future perspective. In P. Moen, G. H. Elder \& K. Liischer (Eds.), Examining lives in context: Perspectives on the ecology of buman development (pp. 599-618).

Washingon, D.C.: American

Psychological Association.

Bronfenbrenner, U. (2005). Bioecological theory of human development. In E. Bronfenbrenner (Ed.), Making buman being human: Bioecological perspectives on buman development (pp. 3015).

Thousand Oaks, CA: Sage.

Broderick, C. B. (1993). Understanding family processes: Basics of family systems theory. Newbury Park, CA: SAGE Publications.

Chalip, L. (2006). Toward a distinctive sport management discipline. Journal of Sport Management, 20, 1-21.

Coakley, J. (1987) Children and the sport socialization process. In Advances in pediatric sport sciences: Volume two: Behavioral issues. Champaign, IL: Human Kinetics.

Coakley, J. (2006). The good father: Parental expectations of youth sport. Leisure Studies, 25(2), 153-163.

Côté, J. (1999). The influence of the family on the development of sport. The Sport Psychologist, 13, 395-417.

Cox, M. I., \& Paley, B. (1997). Families as systems. Annual Review of Psychology, 48, 243-267.

Cox, M. J., \& Paley, B. (2003). Understanding families as systems. Current Directions in Psychological Science, 12(5), 193-196.

Dixon, M. A. (2009). From their perspective: A qualitative examination of physical activity and 
sport for working mothers. Sport

Management Review, 12, 34-48.

Dixon, M. A. \& Bruening, J. E. (2013).

Youth and community sport. In P.

Pederson, J. Parks, J., Quarterman, \&

L. Thibault (Eds.), Contemporary Sport

Management, Fifth Edition.

Champaign, IL: Human Kinetics

Dixon, M.A., Warner, S., \& Bruening, J. (2008). More than just letting them play: The enduring impact of parental socialization in sport for females. Sociology of Sport Journal, 25, 538-559.

Dorsch, T. E., Smith, A. L., \& McDonough, M. H. (2015). Early socialization of parents through organized youth sport. Sport, Exercise, and Performance Psychology. 4(1), 3-18.

Dorsch, T. E., Smith, A. L., \& McDonough, M. H. (2009). Parents' perceptions of child-to-parent socialization in organized youth sport. Journal of Sport and Exercise Psychology, 31, 444-468.

Eisenhardt, K. M. (1989). Building theories from case study research. The Academy of Management Review, 14(4). 532-550.

Engh, F. (1999). Why Johnny hates sports: Youth sports are failing our children and what we can do about it. Garden City Park, NY: Avery Publishing Group.

Epstein, N. B., Bishop, D. S., \& Levin, S. (1978). The McMaster model of family functioning. Journal of Marital and Family Therapy, 4(4), 19-31.

Ericsson, K. A., Krampe, R. T., \& TeschRomer, C. (1993) The role of deliberate practice in the acquisition of expert performance. Psychological Review, 100, 363-406.

Ewing, M. E., Gano-Overway, L. A., Branta, C., \& Seefeldt, V. (2002). The role of sport in youth development. In M. Gatz, M. A. Messner, \& S.J. Ball-Rokeach (Eds.) Pardoxes of youth and sport (pp. 31-47). Albany, NY: State University of New York Press. Fraser-Thomas, J. L., Côté, J., \& Deakin, J. (2008). Examining adolescent sport dropout and prolonged engagement from a developmental perspective. Journal of Applied Sport Psychology, 20, 318-333.

Fraser-Thomas, J. L., Côté, J., \& Deakin, J. (2005) Youth sport programs: An avenue to foster positive youth development. Physical Education and Sport Pedagogy 10(1), 19-40.

Fredricks, J., \& Eccles, J. (2004). Parental influences on youth involvement in sports. In M.R. Weiss (Ed.), Developmental sport and exercise psychology: A lifespan perspective (pp. 145-164). Morgantown, WV: Fitness Information Technology.

Freistadt, J., \& Strohschein, L. (2012). Family structure differences in family functioning: Interactive effects of social capital and family structure. Journal of Family Issues, 34(7), 952-974.

Frey, J. H., \& Eitzen, D. S. (1991). Sport and society. Annual Review of Sociology, 17, 503-522. 
Glaser, B., \& Strauss, A. (1967), The discovery of grounded theory. Chicago, IL: Aldine Publishing Company.

Glaser, B. (1978). Basics of grounded theory analysis: Emergence vs. forcing. Mill Valley, CA: Sociology Press.

Green, B.C., \& Chalip, L. (1997). Enduring involvement in youth soccer: The socialization of parent and child. Journal of Leisure Research, 29(1), 61-77.

Hartmann, D. (2003). Theorizing sport as social intervention: A view from the grassroots. Quest, 55, 118-140.

Hasbrook, C. A. (1986). Reciprocity and childhood socialization into sport. In L. Vander Velden \& J.H. Humphrey (Eds.), Psychology and sociology of sport:

Current selected research. Vol. 1 (pp. 135147). New York: AMS Press.

Hellstedt, J. C. (1995). Invisible players: A family systems model. In S. Murphy (Ed.) Sport Psychology Interventions. (pp. 117-146). Champaign, IL: Human Kinetics.

Hill, M. S. (1988). Marital stability and spouses shared time. Journal of Family Issues, 9, 427-451.

Holt, N. L., Tamminen, K. A., Black, D. E., Mandigo, J. L., \& Fox, K. R. (2009). Youth sport parenting styles and practices. Journal of Sport \& Exercise Psychology, 31(1), 37-59.

Kay, T. (2000). Sporting excellence: A family affair?. European Physical Education Review, 6(2), 151-169.

Lally, P., \& Kerr, G. (2008). The effects of athlete retirement on parents. Journal of Applied Sport Psychology, 20, 42-56. doi:10.1080/10413200701788172 Lavee, Y., McCubbin, H.I., \& Olson, D.H. (1987). The effect of stressful life events and transitions on family functioning and well-being. Journal of Marriage and Family, 49(4), 857-873.

Lim, S. Y., Warner, S., Dixon, M. A., Berg, B., Kim, C., \& Newhouse-Bailey, M. (2011). Sport participation across national contexts: A multilevel investigation of individual and systemic influences on adult sport participation. European Sport Management Quarterly, 11, 197-224.

Minuchin, P. (1985). Families and individual development: Provocations from the field of family therapy. Child Development, 56, 289-302.

Olson, D. H. (2000). Circumplex model of marital and family systems. Journal of Family Therapy, 22, 144-167.

O'Rourke, D. J., Smith, R. E., Smoll, F. L., \& Cumming, S. P. (2011). Trait anxiety in young athletes as a function of parental pressure and motivational climate: is parental pressure always harmful?. Journal of Applied Sport Psychology, 23(4), 398412. DOI: 10.1080/10413200.2011.552089 Orlick, T. D. (1974). An interview schedule designed to assess family sports environment. International Journal of Sport Psychology, 5(1), 13-27.

Orthner, D. K., \& Mancini, J. A. (1991). Benefits of leisure for family 
bonding. In B. L. Driver, P. J. Brown, \& G. L. Peterson (Eds.), Benefits of leisure (pp. 215-301). State College, PA: Venture.

Parsons, T. (1951). The social system. New York: Free Press.

Thomas, G. (2011). A typology for the case study in social science following a review of definition, discourse, and structure. Qualitative inquiry, 17(6), 511-521.

Thompson, S. M. (1999). Mother's Taxi. Albany, NY: State University of New York Press.

Warner, S., Dixon, M., \& Leierer, S. (2015). Using youth sport to enhance parents' sense of community. Journal of Applied Sport Management, 7, 42-61.

Warner, S., \& Leierer, S. (in press). Building Community via Sport for Adolescents. Journal of Applied Sport Management.

Wiersma, L., \& Fifer, A.M. (2008). It's our turn to speak: The joys, challenges, and recommendations of youth sport parents. Journal of Leisure Research, 40(4), 505-530.

Zabriskie, R. B., \& McCormick, B. P. (2001). The influences of family leisure patterns on perceptions of family functioning. Family Relations, 50, 281-289 


\section{Tables}

Table 1

Participant Table (by Family)

\begin{tabular}{|c|c|c|c|c|c|c|c|}
\hline & $\begin{array}{c}\text { Married } \\
\text { (years) }\end{array}$ & $\begin{array}{l}\text { Father's } \\
\text { Occupation }\end{array}$ & $\begin{array}{l}\text { Mother's } \\
\text { Occupation }\end{array}$ & $\begin{array}{l}\text { Annual } \\
\text { Income }\end{array}$ & Child (years) & Child (years) & Child (years) \\
\hline 1 & 16 & $\begin{array}{l}\text { Restaurant } \\
\text { Owner }\end{array}$ & $\begin{array}{l}\text { Stay at Home } \\
\text { Mom }\end{array}$ & $\begin{array}{l}\text { Over } \\
\$ 200,000\end{array}$ & $\begin{array}{l}\text { Son }(13)- \\
\text { elite } \\
\text { baseball }\end{array}$ & $\begin{array}{l}\text { Son }(12)- \\
\text { recreational } \\
\text { lacrosse }\end{array}$ & \\
\hline 2 & 15 & $\begin{array}{l}\text { Software } \\
\text { Engineer }\end{array}$ & $\begin{array}{l}\text { Stay at Home } \\
\text { Mom }\end{array}$ & $\begin{array}{l}\text { Over } \\
\$ 200,000\end{array}$ & $\begin{array}{l}\text { Daughter } \\
\text { (13) - Cello }\end{array}$ & $\begin{array}{l}\text { Daughter } \\
\text { (11) - elite } \\
\text { soccer }\end{array}$ & $\begin{array}{l}\text { Son }(9)- \\
\text { recreational } \\
\text { football }\end{array}$ \\
\hline 3 & 18 & $\begin{array}{l}\text { Student } \\
\text { Pastor }\end{array}$ & Teacher & $\begin{array}{l}\text { Under } \\
\$ 50,000\end{array}$ & $\begin{array}{l}\text { Daughter } \\
(15) \text { - club } \\
\text { volleyball }\end{array}$ & $\begin{array}{l}\text { Son (10) - } \\
\text { elite baseball } \\
\text { and football }\end{array}$ & \\
\hline 4 & 19 & $\begin{array}{l}\text { Senior } \\
\text { Technical } \\
\text { Writer }\end{array}$ & Letter Carrier & $\$ 110,000$ & $\begin{array}{l}\text { Daughter } \\
(15) \text { - elite } \\
\text { soccer }\end{array}$ & $\begin{array}{l}\text { Daughter } \\
\text { (13) - elite } \\
\text { soccer }\end{array}$ & Son (8) \\
\hline 5 & 13 & $\begin{array}{l}\text { Food } \\
\text { Service } \\
\text { Executive }\end{array}$ & Midwife & $\$ 100,000$ & $\begin{array}{l}\text { Daughter } \\
(18) \text { - } \\
\text { recreational } \\
\text { hockey }\end{array}$ & $\begin{array}{l}\text { Son (14) - } \\
\text { elite hockey }\end{array}$ & \\
\hline 6 & 17 & $\begin{array}{l}\text { Tax } \\
\text { Enforcem } \\
\text { ent Officer }\end{array}$ & $\begin{array}{l}\text { Administrative } \\
\text { Assistant }\end{array}$ & $\$ 60,000$ & $\begin{array}{l}\text { Daughter } \\
\text { (14) elite } \\
\text { soccer }\end{array}$ & $\begin{array}{c}\text { Daughter (9) } \\
\text { elite soccer }\end{array}$ & \\
\hline 7 & 17 & Laborer & $\begin{array}{l}\text { Substitute } \\
\text { Teacher }\end{array}$ & $\$ 100,000$ & $\begin{array}{l}\text { Son (16) - } \\
\text { elite } \\
\text { swimmer }\end{array}$ & $\begin{array}{l}\text { Daughter } \\
(14) \text { - } \\
\text { recreational } \\
\text { swimmer }\end{array}$ & $\begin{array}{l}\text { Daughter (9) } \\
\text { - recreational } \\
\text { swimmer }\end{array}$ \\
\hline
\end{tabular}

